\title{
A interprofissionalidade como estrategias para mudanças no ensino uma proposta do PET- graduaSUS/UFPB
}

Rafael da Costa Santos, Rossana Maria Souto Maior Serrano, Anna Luiza Castro Gomes, Oriana Deyze Correia Paiva Leadebal

\section{Resumo}

A Educação Interprofissional (EIP) é tida como uma importante estratégia para formar recursos humanos para o trabalho em equipe, prática essencial para a integralidade no cuidado em saúde. Atualmente a formação com intensa carga horária, isolada e circunscrita à própria área de atuação tem levado os profissionais de saúde a atuarem de forma pontual e restrita à suas especialidades. Diversos autores destacam que a EIP contribui para uma formação fundamentada na colaboração e no reconhecimento de interdependência das áreas predominam sobre a competição e a fragmentação. Este trabalho apresenta o relato da experiência de criação de uma disciplina multidisciplinar e interprofissional para os cursos de saúde da UFPB. A proposta nasce na Oficina: Construindo a Educação Interprofissional nos Cursos de Saúde que contou com a participação de professores, estudantes e preceptores, promovendo um espaço para relatos de experiências exitosas com a EIP, além de reflexões sobre o processo de formação em saúde da UFPB. Como resultado da oficina foi estruturado um componente flexível, com o envolvimento de professores dos cursos envolvidos no PETGRADUASUS. Foram realizadas reuniões para construção do programa e metodologia, na perspectiva da integralidade do cuidado, integração entre os participantes e está fundamentada no cuidado interdisciplinar, na integralidade e no uso de metodologias ativas. O componente busca desenvolver competências comuns a todas as profissões, competências colaborativas e o respeito as competências específicas de cada área profissional. Foram realizadas reuniões com trabalhadores e residentes objetivando a identificação de casos e vivencias a serem utilizados na prática de ensino da disciplina. O componente tem carga horária de 45 horas, conta com o envolvimento de 6 professores da área de saúde pública, está estruturado com momentos de integração e dispersão. A dispersão ocorrerá em grupos multiprofissionais com a orientação de um docente e inserção nas vivencias da rede SUS.

Descritores: Relações Interprofissionais, Educação Superior, Educação Baseada em Competências, Pessoal de Saúde 